\title{
Actividad antimicrobiana de hongos endófitos de las plantas medicinales Mammea americana (Calophyllaceae) y Moringa oleifera (Moringaceae)
}

Wilmer Giovanny Mosquera1, Libeth Yajaira Criado ${ }^{2}$, Beatriz Elena Guerra1

${ }^{1}$ Grupo de Investigación en Biotecnología, Agroambiente y Salud - Microbiota; maestría en Investigación de Enfermedades Infecciosas, Universidad de Santander, Bucaramanga, Colombia

${ }^{2}$ Grupo Salud Comunid-UDES, Escuela de Medicina, Universidad de Santander, Bucaramanga, Colombia

Introducción. Las enfermedades infecciosas son una causa importante de muertes en el mundo. La resistencia antimicrobiana es un problema global, por lo que es conveniente la investigación de nuevas fuentes de agentes antimicrobianos de origen natural potencialmente efectivos.

Objetivo. Evaluar la actividad antimicrobiana de hongos endófitos de Mammea americana y Moringa oleifera en la cepa sensible (ATCC 29213) y en la cepa resistente (USb003) de Staphylococcus aureus, así como en la cepa sensible (ATCC 25922) y la cepa resistente (USb007) de Escherichia coli.

Materiales y métodos. Se aislaron 14 hongos endófitos de las hojas, semillas y tallos de las dos plantas en estudio. Se evaluó su actividad antimicrobiana mediante la formación de halos de sensibilidad por ensayo dual in vitro y pruebas con extractos etanólicos crudos provenientes de los endófitos a los que se les evaluó la concentración mínima inhibitoria (CMI), la concentración bactericida mínima (CBM) y la citotoxicidad.

Resultados. Tres extractos etanólicos de Penicillium sp., Cladosporium sp. (001) y Cladosporium sp. (002) presentaron mayores halos de inhibición en cepas sensibles y resistentes de E. coli y $S$. aureus. La CMI y la CBM halladas fueron estadísticamente significativas $(p \leq 0,05)$, comparadas con el control de gentamicina. Las pruebas de citotoxicidad (concentración citotóxica, $\mathrm{CC}_{50}>1.000$ ) demostraron que los hongos endófitos poseen características bactericidas y no ocasionan daño alguno.

Recibido: 15/08/2018

Aceptado: $19 / 06 / 2019$

Publicado: 19/07/2019

Citación:

Mosquera WG, Criado LY, Guerra BE. Actividad antimicrobiana de hongos endófitos de las plantas medicinales Mammea americana (Calophyllaceae) y Moringa oleifera (Moringaceae). Biomédica. 2020:40:55-71.

https://doi.org/10.7705/biomedica.4644

\section{Correspondencia:}

Beatriz Elena Guerra, Grupo Biotecnología, Agroambiente y Salud -Microbiota, Universidad de Santander, Calle 107 No 21-a-05, Campus Universitario Lagos del Cacique, Bucaramanga, Colombia

Teléfono: (577) 651 6500, extensión 1477

bguerra@udes.edu.co

Contribución de los autores:

Wilmer Giovanny Mosquera: recopilación de la información, aislamiento de endófitos y pruebas antimicrobianas

Libeth Yajaira Criado: diseño y proceso de los estudios de actividad antimicrobiana

Beatriz Elena Guerra: concepción y diseño del tema de investigación e identificación de hongos endófitos Todos los autores participaron en el análisis de datos y la escritura del manuscrito.

Financiación:

Maestría en Investigación de Enfermedades Infecciosas y Laboratorio de Investigación e Innovación en Biotecnología Agroambiental, LIIBAAM, Universidad de Santander

\section{Conflicto de intereses:}

Los autores declaramos no tener conflictos de intereses financieros ni personales que pudieran haber influido en el desarrollo de esta investigación.
Conclusión. Se halló una fuente de metabolitos secundarios activos con propiedades hallazgos son importantes para continuar con la identificación química de los compuestos y el estudio de sus mecanismos de acción en estas plantas en las que el aislamiento de endófitos ha sido escaso.

Palabras clave: farmacorresistencia microbiana; endófitos; plantas medicinales; Escherichia coli; Staphylococcus aureus.

\section{Antimicrobial activity of endophytic fungi from the medicinal plants Mammea americana (Calophyllaceae) and Moringa oleifera (Moringaceae)}

Introduction: Infectious diseases represent one of the leading causes of death worldwide. Considering the growing global challenge of antimicrobial resistance, research into new sources of potentially effective antimicrobial agents from natural origins is of great importance for world health.

Objective: To evaluate the antimicrobial activity of endophytic fungi from Mammea americana and Moringa oleifera upon Staphylococcus aureus (ATCC 29213), S. aureus (resistant strain USb003), Escherichia coli (ATCC 25922), and E. coli (resistant strain USb007).

Materials and methods: We isolated endophytic fungi from the leaves, seeds, and stems of the two plants under study. We evaluated their antimicrobial activity through the formation of sensitivity haloes in dual tests in vitro, as well as in trials using crude ethanolic extracts from the endophytes. The minimum inhibitory concentration (MIC), minimum bactericidal concentration (MBC), and cytotoxicity o the substances were analyzed.

Results: Three ethanolic extracts of Penicillium sp., Cladosporium (001), and Cladosporium (002) exhibited the greatest inhibition halos in sensitive and resistant strains of $E$. coli and S. aureus. The MIC and CBM found were statistically significant $(p \leq 0.05)$ compared with the gentamicin control. Furthermore, the cytotoxicity test results of CC50>1,000 demonstrated that the endophytic fungi studied exhibit bactericidal characteristics without causing unintended damage.

Conclusion: The endophytic fungi $M$. oleifera and $M$. americana represent a source of active secondary metabolites with antimicrobial and non-toxic properties. In light of these findings, further research should proceed with chemical identification of the compounds and antimicrobianas y no tóxicas en los hongos endófitos de $M$. oleifera y $M$. americana; estos 
the study of their mechanisms of action, especially given the paucity of current scientific knowledge concerning the isolation of endophytes in these plants.

Keywords: Drug resistance, microbial; endophytes; plants, medicinal; Escherichia coli, Staphylococcus aureus.

La resistencia a los antibióticos es uno de los temas más importantes en salud pública a nivel mundial y su incremento incide en la prevalencia de las enfermedades infecciosas. La resistencia a los antibióticos ocurre ya sea por mutaciones o por adquisición de genes que la confieren mediante transferencia horizontal, siendo esta última el factor más importante (1). Se sabe que, históricamente, las plantas han tenido un papel importante como fuente natural de compuestos con actividad antimicrobiana; sin embargo, se estima que solo se ha investigado entre el 10 y el $15 \%$ de las especies de plantas superiores que la exhiben (2). Hoy se reconoce que un gran número de los compuestos bioactivos de las plantas son producidos por las comunidades microbianas endófitas albergadas en sus tejidos (3).

La presencia de hongos endófitos se reportó por primera vez en 1898, aunque el concepto de 'endófito' ya se había descrito en 1866 (4), sin que en ese momento se reconociera su importancia. Años más tarde comenzaron a ser objeto de investigación y se registró su capacidad para colonizar tejidos de plantas sin causar enfermedad (5).

Estas comunidades de microorganismos endófitos constituyen un importante campo de investigación farmacológica por la producción de metabolitos secundarios, agentes antimicrobianos que contribuyen a la disminución de las infecciones causadas por agentes patógenos adyacentes. En la relación entre los hongos endófitos y las plantas se ha verificado una producción activa de metabolitos secundarios segregados por los dos tipos de organismos: así, el vegetal proporciona defensas y el hongo fomenta la producción de metabolitos de características virulentas como los fitotóxicos, y algunas enzimas dañinas como las exoenzimas. Esta relación se conoce como endofítica y, si no es equilibrada, el hongo actúa como agente patógeno, dada su capacidad virulenta $(6,7)$. Se ha subrayado que las interacciones entre los endófitos y las plantas que los alojan contribuyen a la producción conjunta de diversas moléculas bioactivas (8).

En un número considerable de publicaciones, se ha dado a conocer la importancia de estos microorganismos en la agricultura y en la medicina. Aunque muchos de ellos no se han estudiado a fondo, sí han evidenciado su condición de portadores de agentes productores de metabolitos bioactivos útiles para la defensa de sus huéspedes frente a los agentes patógenos y como reservorios de diversidad genética, habiéndose comprobado que sus metabolitos se activan al interactuar con las vías metabólicas de su huésped (9).

Se ha demostrado que los metabolitos secundarios biosintetizados por hongos endófitos poseen una gran actividad biológica, lo que evidencia su relevancia como agentes fitotóxicos y antimicrobianos, y amerita que se siga explorando e investigando sobre nuevos metabolitos activos producidos por los diferentes microorganismos endófitos de tejidos vegetales, en especial de plantas tropicales.

Mammea americana $L$ se conoce en América como una planta medicinal. Se cultiva en las Bahamas y, en menor escala, en Venezuela, Guyana, Surinam, Guyana Francesa, Ecuador y el norte de Brasil. En Colombia, se encuentra en los bosques seco tropical, húmedo tropical, húmedo premontano 
y muy húmedo premontano (10), y se la conoce como mamey de Cartagena de Indias, o como Mammee-apple (11). La madera es de beneficio económico y sus frutos, de buen sabor y gran valor nutricional, se consumen en varias regiones, y se componen de $18 \%$ de cáscara, $20 \%$ de semilla y $62 \%$ de pulpa. Mammea americana se usa en la medicina alternativa para el tratamiento de las parasitosis, la flema, el exceso de ácido úrico, la fiebre, la hipertensión arterial, las infecciones de la piel, el raquitismo y la pérdida de cabello, entre otros. Posee compuestos cumarínicos (cumarinas de Mammea), a los que se les han atribuido propiedades antioxidantes, antimicrobianas, insecticidas, anticancerígenas, antitumorales y antifúngicas (12), a pesar de lo cual poco o nada se han estudiado y aislado sus hongos endófitos.

Otra planta medicinal de importantes propiedades es Moringa oleifera Lam, originaria de Kerala, India, que ha sido introducida en varias partes del mundo y en Suramérica desde México hasta Perú, Paraguay y Brasil (13). Se le considera un árbol capaz de adaptarse bien a diferentes climas, aunque es más frecuente en climas templados y tolera menos las bajas temperaturas. Es muy resistente a los diferentes agentes patógenos que la puedan afectar y sus hojas poseen una gran cantidad de proteínas, vitaminas, minerales y aminoácidos (14). El aceite de sus semillas se utiliza mucho por su contenido de ácido oleico (73\%), similar al de la oliva. En sus semillas se han encontrado coagulantes naturales, y se utilizan para la limpieza y aclaramiento de aguas, por lo que se emplea para mejorar las condiciones sanitarias en algunos países menos desarrollados (15).

Moringa oleifera ha sido objeto de estudios por la actividad antimicrobiana de sus endófitos, aislados de diferentes partes de la planta, los cuales se encuentran en comunidades fúngicas $(16,17)$ y en comunidades bacterianas. En varios estudios se ha propuesto su utilización con fines nutricionales y medicinales, sin embargo, poco se sabe de ellos y de la obtención de metabolitos activos potencialmente útiles como antimicrobianos. Los metabolitos secundarios que más se han obtenido de $M$. oleifera han sido los flavonoides, los flavonoles, las antocianinas, los polifenoles, los alcaloides y los taninos (18), todos de gran importancia en la agricultura y en la medicina.

La Organización Mundial de la Salud (OMS) ha incluido a Escherichia coli y Staphylococcus aureus en el grupo más importante de bacterias causantes de infecciones y resistencia a fármacos. Escherichia coli coloniza el sistema gastrointestinal de seres humanos y otros animales, y está implicada en una serie de enfermedades que incluyen infecciones de las vías urinarias, septicemia, neumonía, meningitis neonatal, peritonitis y gastroenteritis (19). Es agente causal de un porcentaje importante de la enfermedad diarreica en el mundo y se estima que ocasiona, aproximadamente, 775.000 muertes al año, principalmente entre la población infantil de los países menos desarrollados (20). Por su parte, las infecciones de las vías urinarias afectan a pacientes sintomáticos y asintomáticos (21), con gran prevalencia en mujeres y niñas.

Las cepas patógenas de E. coli han demostrado su capacidad de resistencia a diversos fármacos de los empleados para combatirla (22). Se han descrito varios mecanismos de resistencia (entre ellos, desvío de una etapa metabólica, alteración de blancos, inactivación enzimática y disminución de la acumulación intracelular del antimicrobiano) a medicamentos como la tetraciclinas, los betalactámicos, el cloranfenicol, las sulfonamidas, el trimetoprim y los aminoglucósidos (23). 
Staphylococcus aureus se encuentra principalmente en los tejidos de la piel sana y, por lo general, no provoca daño alguno; sin embargo, puede generar infecciones en pacientes inmunosuprimidos cuando se pierden las barreras naturales o en caso de trauma, siendo una de las principales causas de infección en sitios quirúrgicos y en infecciones asociadas con la atención en salud (24). Varias cepas de $S$. aureus han evolucionado gradualmente y sobreviven a la acción de los betalactámicos, como oxacilina, meticilina y nafcilina, y de otro tipo de antibióticos (25). En algunos estudios se ha demostrado que dicha resistencia está regulada y codificada por casetes genéticos cromosómicos.

En los países desarrollados, se considera que la concentración inhibitoria mínima (CMI) de la vancomicina es de $\geq 16 \mu \mathrm{g} / \mathrm{ml}$; si esta es de 2 a $8 \mu \mathrm{g} / \mathrm{ml}$, la resistencia es moderada, y hay sensibilidad si la CIM es de $2 \mu \mathrm{g} / \mathrm{ml}$ o menor (26), en tanto que el mecanismo de resistencia a los aminoglucósidos, las tetraciclinas y la eritromicina se da mediante plásmidos. La resistencia a la meticilina es una de las más importantes, pues para los pacientes infectados representa una probabilidad de mortalidad del $64 \%$ (27).

El problema de la resistencia bacteriana ha incentivado la investigación de nuevas fuentes de antibióticos de origen natural. En dicho contexto, el objetivo de este trabajo se centró en el análisis de la actividad antibacteriana de los hongos endófitos aislados de dos plantas medicinales, M. oleifera y M. americana, siendo la primera vez que la actividad antimicrobiana de esta última se reporta.

\section{Materiales y métodos}

Se llevaron a cabo la búsqueda, el aislamiento y la caracterización a nivel de morfoespecie de hongos endófitos en hojas, tallos y semillas de $M$. americana y $M$. oleifera. Se procesaron, en promedio, 60 muestras vegetales para aislarlos y determinar su actividad antimicrobiana en las cepas sensibles (ATCC 29213) de S. aureus y (ATCC 25922) de E. coli, así como en las cepas resistentes (USb003) de S. aureus y (USb007) de E. coli. Se hicieron pruebas de concentración inhibitoria mínima $(\mathrm{CMI})$, concentración bactericida mínima (CBM) y citotoxicidad en las cepas sensibles.

\section{Recolección de muestras vegetales}

La recolección de tejidos vegetales (hojas, semillas y tallos) de $M$. americana y $M$. oleifera se hizo totalmente al azar en 20 árboles visiblemente sanos. Las muestras de $M$. americana se obtuvieron en el municipio de Turbaco, departamento de Bolívar (10¹9'30"00 N y 1¹7'29" O), en la Costa Atlántica colombiana y, las de M. oleifera, en plantaciones de la finca Manzanares, localizada en el municipio de Floridablanca, Santander (0706'35,6”'N y 7305'58'E).

\section{Aislamiento de hongos endófitos}

Las muestras de los diversos tejidos de las dos plantas se cortaron en segmentos de $1 \mathrm{~cm}$, se lavaron y desinfectaron superficialmente utilizando el método descrito por Unterseher, et al. (28), con algunas modificaciones en los porcentajes y tiempos de acción del alcohol y el hipoclorito.

Cuatro segmentos vegetales se transfirieron de forma aséptica al medio de cultivo micológico agar de papa y dextrosa (APD) con suplemento de cloranfenicol a 100 ppm; luego se colocaron de forma equidistante y se incubaron a $30^{\circ} \mathrm{C}$ durante 20 días. El crecimiento de los endófitos se registró diariamente. 
Para el aislamiento de colonias puras, se procedió a hacer repiques en nuevos medios micológicos a partir de las puntas de las hifas de las colonias fúngicas visiblemente diferentes y a sembrar en medio APD por triplicado con suplemento de $16 \mu \mathrm{g} / \mathrm{ml}$ de cloranfenicol a $25^{\circ} \mathrm{C}$, durante 15 días hasta obtener cultivos puros.

\section{Prueba de preselección de endófitos}

La preselección de los endófitos con posible actividad antimicrobiana se determinó utilizando cepas sensibles de $S$. aureus (ATCC 29213) y de $E$. coli (ATCC 25922) y cepas de origen clínico resistentes a antibióticos de la colección de bacteriología de la Universidad de Santander: S. aureus (USb003) y E. coli (USb007). Se tomaron porciones de cada uno de los hongos endófitos aislados previamente en cultivos puros de agar papa-dextrosa y con ayuda de la punta de pipetas estériles, las porciones se transfirieron a la superficie de distintas placas de Petri que contenían el medio de cultivo Müller-Hinton. Estos medios de cultivo fueron previamente inoculados y sembrados con cada una de las bacterias en estudio, utilizando el método de Kirby-Bauer. Los cultivos duales (bacteria-hongo) se dejaron a $37^{\circ} \mathrm{C}$ durante 12 a 18 horas para favorecer el crecimiento bacteriano; y la bioactividad de los hongos se evalúo seleccionando aquellas cepas que produjeron mayor halo de actividad.

Todas las pruebas se hicieron por triplicado para comparar el valor de las medias de los halos de cada uno de los endófitos aislados.

\section{Identificación de los endófitos}

Los hongos endófitos que mostraron actividad en la prueba de preselección con base en los halos, se identificaron hasta el nivel de morfoespecie según sus características macroscópicas (color y aspecto de las colonias tanto en el reverso como el anverso, presencia de pigmentos que se difunden en el medio) y características microscópicas, tales como estructuras de reproducción asexual, aparición de conidias, y tamaño, forma y color de las esporas, observadas con un microscopio Nikon (Eclipse-Ni-u) ${ }^{\mathrm{TM}}$ a 10X y 40X.

Se utilizaron claves internacionales $(29,30)$ disponibles en línea para la identificación de los endófitos hasta el nivel de morfoespecie.

\section{Obtención de extractos etanólicos fúngicos y pruebas de actividad antimicrobiana}

Siguiendo los protocolos estandarizados para la obtención de biomasa de hongos endófitos utilizados en el Laboratorio de Micología de la Universidad de Santander, se consideró un promedio de 30 cultivos en APD y un crecimiento del micelio de 15 a 20 días, para obtener biomasa de cada una de las cepas fúngicas preseleccionadas.

Para la preparación inicial de soluciones madre de extracto etanólico crudo de endófitos, se consideró una relación entre peso y volumen $(\mathrm{P} / \mathrm{V})$ de 1:1 de biomasa y etanol; posteriormente, se agitó durante las primeras 24 horas, al cabo de las cuales se detuvo la agitación y los extractos se llevaron a tres partes de etanol y una de biomasa fúngica (3:1) para, luego, continuar la agitación durante 48 horas más. A continuación, se mantuvieron refrigerados en frascos de vidrio ámbar durante 15 días hasta su separación con el método de filtración a través de una membrana Millipore de $22 \mu \mathrm{m}$. Posteriormente, el filtrado se llevó al evaporador rotativo (Rotavapor R-300 ${ }^{\mathrm{TM}}$ - Buchi). Los extractos secos se pesaron y almacenaron a $4{ }^{\circ} \mathrm{C}$ hasta su posterior utilización. 


\section{Determinación de la actividad antibacteriana de los extractos de hongos crudos}

La actividad antibacteriana de los metabolitos secundarios extraídos de los hongos endófitos de $M$. americana y $M$. oleífera, se analizó frente a las bacterias sensibles y resistentes a antibióticos mediante el método de difusión del pozo de agar. Los cultivos bacterianos se extendieron en placas de agar Müller-Hinton, luego se perforaron los pozos en las placas de agar y se vertieron en microplacas tres concentraciones del extracto crudo de $35 \mu \mathrm{l}, 70$ $\mu \mathrm{l}$ y $105 \mu \mathrm{l}$. La actividad antibacteriana se detectó después de una incubación de 24 a 48 horas a $37^{\circ} \mathrm{C}$. La presencia de una zona de aclaramiento en las placas, se usó como indicador de la naturaleza antibiótica y bioactiva de los extractos de endófitos fúngicos. Como control positivo se usó gentamicina y, como control negativo, dimetilsulfóxido (DMSO). Se llevaron a cabo tres réplicas de cada prueba de actividad antibacteriana.

\section{Determinación de las concentraciones inhibitoria y bactericida mínimas}

Las concentraciones mínimas, inhibitoria (CIM) y bactericida (CBM), de los extractos etanólicos crudos, se determinaron mediante microdilución según las normas del National Committee for Clinical Laboratory Standards (NCCLS, 2004), y se evaluaron en las cepas E. coli (ATCC 25922) y $S$. aureus (ATCC 29213), siguiendo lo sugerido por el Clinical and Laboratory Standards Institute (CLSI).

Después de la incubación bajo condiciones apropiadas, la concentración más baja de extracto que inhibió el crecimiento visible de cada una de las bacterias en estudio, se registró como la CIM, en tanto que la concentración bactericida mínima (CBM) se halló a partir de las pruebas de CIM mediante dilución en caldo de cultivo secundario en placas de agar. La gentamicina se usó como agente antibacteriano estándar.

Los experimentos se hicieron por duplicado en cada placa y en tres momentos diferentes con los extractos etanólicos de los hongos que presentaron mayores halos de inhibición en las bacterias evaluadas.

\section{Pruebas de citotoxicidad}

Los extractos fúngicos con mayor actividad inhibitoria en cada una de las bacterias evaluadas in vitro, se sometieron a las pruebas de citotoxicidad utilizando la línea celular VERO (células de riñón de mono verde: Cercopithecus aethiops, ATCC: CCL-81). Los cultivos se mantuvieron con medio esencial mínimo de Eagle modificado por Dulbecco (DMEM) y suero fetal bovino al $5 \%$, y se incubaron a $37^{\circ} \mathrm{C}$ en $5 \%$ de $\mathrm{CO}_{2}$ en cajas de cultivo celular Nunc ${ }^{\mathrm{TM}}$ de $25 \mathrm{ml}$. Se trasladaron a una placa de 96 pozos de $4,0 \times 10^{5}$ células por pozo y se agregaron $100 \mu \mathrm{l}$ de los extractos fúngicos en concentraciones de $4.000 \mu \mathrm{g} / \mathrm{ml}$ en DMSO al $10 \% \mathrm{v} / \mathrm{v}$ y en dilución seriada hasta los $400 \mu \mathrm{g} / \mathrm{ml}$, y se mantuvieron en iguales condiciones de suplementos e incubación durante 72 horas, al cabo de las cuales se contaron las células viables por exclusión con azul de tripano. En cada caso se determinó la concentración citotóxica media $\left(\mathrm{CC}_{50}\right)$, la cual indica la reducción del número de células viables al 50 \%.

Como control negativo, se utilizó el cultivo celular sin adición de la muestra, al cual también se le hizo conteo celular como punto de comparación del crecimiento logarítmico a las 72 horas. 
Todas las pruebas se llevaron a cabo por duplicado. En el análisis de los datos de citotoxicidad, se utilizó el programa estadístico MsxlfitTM (ID Business Solution, Guildford, UK) para calcular, mediante análisis de regresión sigmoidea, la concentración citotóxica media $\left(\mathrm{CC}_{50}\right)$ de cada uno de los extractos etanólicos de hongos endófitos de $M$. americana y M. oleifera.

Los experimentos se realizaron por triplicado en tres momentos independientes y con tres extractos de hongos endófitos seleccionados, y la toxicidad se evaluó en las cepas ATTCC en estudio.

\section{Datos estadísticos}

La actividad antimicrobiana de los extractos se evaluó con el programa estadístico Stata $14^{\mathrm{TM}}$, para determinar promedios, medianas, rangos y comparación de halos de sensibilidad en las bacterias (sensibles y resistentes) utilizadas en las pruebas. La prueba estadística t de Student se empleó para comparar los halos de inhibición en la preselección mediante ensayo dual, y las de Mann-Whitney y de Kruskal-Wallis, para comparar los halos de inhibición con cada uno de los extractos fúngicos, utilizando como control la gentamicina y considerando como referencia los datos de halos de sensibilidad y resistencia descritos en la literatura especializada.

\section{Resultados}

\section{Porcentajes de aislamientos de endófitos}

En $M$. oleífera se aislaron endófitos de los tres tejidos vegetales, con un porcentaje mayor en hojas (58\%); en los tallos fue de $34 \%$ y en las semillas, de $8 \%$. En M. americana, por el contrario, la mayoría (65\%) de los endófitos se obtuvieron de la semilla, y el resto se obtuvo de las hojas (figura 1).

\section{Pruebas de preselección por ensayo dual}

Las pruebas de preselección por ensayo dual in vitro con base en la formación de halos de inhibición del crecimiento bacteriano por parte de los hongos endófitos, se analizaron mediante la prueba t de Student, la cual permitió preseleccionar los 14 hongos endófitos (cuadro 1) aislados de los diferentes tejidos vegetales con los mayores halos de inhibición del crecimiento bacteriano en cepas sensibles y resistentes a antibióticos de E. coli y $S$. aureus.

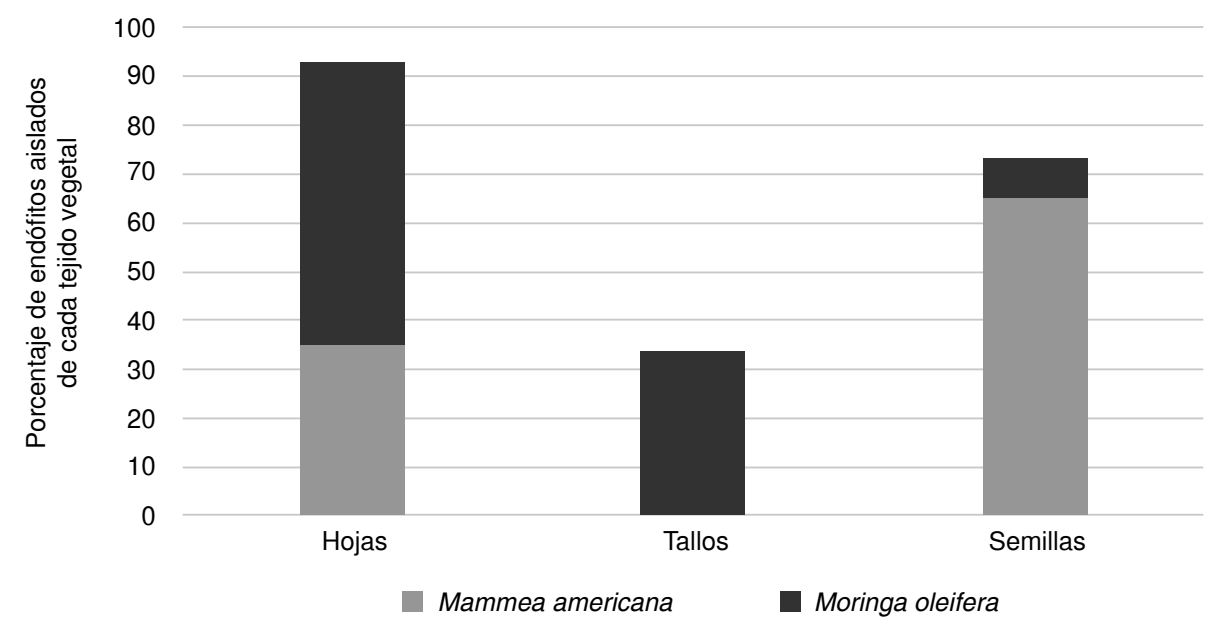

Figura 1. Porcentaje de hongos endófitos aislados en Moringa oleifera y Mammea americana 


\section{Actividad antibacteriana de extractos crudos de endófitos según halos de inhibición}

En los cuadros 2 y 3 , se comparan los halos de inhibición del crecimiento bacteriano de las cepas sensibles y resistentes de $S$. aureus y E. coli con diferentes concentraciones de extractos etanólicos de hongos endófitos y el control de gentamicina (prueba estadística de Mann-Whitney).

Siete de los extractos de endófitos fúngicos estudiados como antibacterianos presentaron halos de inhibición para las cepas sensibles y resistentes de $S$. aureus (cuadro 2), en tanto que 11 cepas de E. coli (cuadro 3) mostraron actividad antimicrobiana, según se evidenció con la formación de halos de inhibición del crecimiento.

La actividad antimicrobiana de los extractos etanólicos fúngicos de los endófitos fue diferente para las cepas de $S$. aureus sensibles y para las resistentes, con un rango de halos de inhibición de 13 a $24 \mathrm{~mm}$ y de 12 a 25 $\mathrm{mm}$, respectivamente, siendo estos valores estadísticamente significativos con relación al control de gentamicina (cuadro 2).

Un comportamiento similar se observó en las pruebas de inhibición del crecimiento bacteriano en las cepas de E. coli con los diferentes extractos fúngicos de los endófitos, los cuales presentaron halos de inhibición en rangos similares a los observados para las cepas de $S$. aureus (cuadro 3 ).

En cuanto a la actividad antimicrobiana de los extractos fúngicos de los endófitos en las cepas de $S$. aureus, los extractos HEHMa6, HESMo8, HETMo9 y HESMa10 evidenciaron actividad inhibitoria frente a las cepas sensibles y a las resistentes. En cuanto a E. coli, el endófito HEHMa6 presentó un halo de inhibición significativamente mayor $(p=0,0339)$ en las dos cepas: la sensible y la resistente, en comparación con el control de gentamicina.

Por otro lado, al comparar los halos de inhibición de los tres tipos de concentraciones de cada hongo mediante la prueba estadística de KruskalWallis, se observó que, frente a la cepa sensible de E. coli (ATCC 29213),

Cuadro 1. Preselección por ensayo dual de la actividad antimicrobiana de hongos endófitos de Mammea americana y Moringa oleifera en cepas de Escherichia coli y Staphyloccocus aureus sensibles y resistentes

\begin{tabular}{lccccc}
\hline $\begin{array}{l}\text { Hongos } \\
\text { endófitos }\end{array}$ & $\begin{array}{c}\text { Tejido de } \\
\text { aislamiento de } \\
\text { los endófitos }\end{array}$ & $\begin{array}{c}\text { E. coli sensible } \\
\text { (ATCC 29213)Tamaño } \\
\text { de halos (mm) }\end{array}$ & $\begin{array}{c}\text { E. coli resistente } \\
\text { (USb007) Tamaño } \\
\text { de halos (mm) }\end{array}$ & $\begin{array}{c}\text { S. aureus sensible } \\
\text { (ATCC 29213) Tamaño } \\
\text { de halos (mm) }\end{array}$ & $\begin{array}{c}\text { S. aureus resistente } \\
\text { (USb003) Tamaño } \\
\text { de halos }(\mathbf{m m})^{\star *}\end{array}$ \\
\hline HESMa1 & Semilla & 25 & 13,6 & 25 & 24,3 \\
HEHMo2 & Hojas & 28,3 & 13,3 & 28,3 & 25,3 \\
HEHMo3 & Hojas & 24,3 & 17,6 & 25 & 23,6 \\
HEHMa4 & Hojas & 23,3 & 16,3 & 23,6 & 23,6 \\
HESMa5 & Semilla & 30,6 & 22,3 & 24,6 & 25 \\
HEHMa6 & Hojas & 30,3 & 19 & 23,3 & 23,3 \\
HETMo7 & Tallo & 25 & 11,6 & 29 & 28,6 \\
HESMo8 & Semilla & 27,6 & 18,6 & 28,6 & 28 \\
HETMo9 & Tallo & 27 & 17,3 & 26,3 & 26,6 \\
HESMa10 & Semilla & 20,6 & 16,3 & 32,6 & 27,6 \\
HEHMo11 & Hojas & 25,6 & 22,6 & 29 & 32 \\
HEHMo12 & Hojas & 31,3 & 19,6 & 25,6 & 25,6 \\
HESMa13 & Semilla & 30 & 21,6 & 26 & 25,6 \\
HEHMa14 & Hojas & 14 & 12,6 & 26,8 & 26 \\
Valor promedio & & 22 & 19 & & 27,75 \\
\hline
\end{tabular}

HE: hongo endófito; H: hoja; T: tallo; S: semilla; Mo: M. oleifera; Ma: $M$. americana;

$\mathrm{mm}^{\star *}$ : promedio del valor de halos en tres réplicas. Control de gentamicina en cepas sensibles de $S$. aureus: $22 \mathrm{~mm}$. Control de gentamicina en cepas sensibles de E. coli: $23 \mathrm{~mm}$. Control de gentamicina en cepas resistentes de E. coli y S. aureus: $00 \mathrm{~mm}$ 
Cuadro 2. Inhibición del crecimiento de las cepas sensibles y resistentes de Staphylococcus aureus con extractos de hongos endófitos, comparada con el control de gentamicina

\begin{tabular}{|c|c|c|c|c|c|c|}
\hline $\begin{array}{l}\text { Codificación } \\
\text { fúngica }\end{array}$ & $\begin{array}{c}\text { Extracto } \\
\text { de hongos } \\
\text { endófitos }(\mu \mathrm{l})\end{array}$ & $\begin{array}{c}\text { S. aureus } \\
\text { (ATCC 29213) mm } \\
\text { mediana (min.-máx.) }\end{array}$ & $\begin{array}{c}\text { S. aureus } \\
\text { (USb003) mm } \\
\text { mediana (min.-máx.) }\end{array}$ & $\begin{array}{c}\text { Valor de } p \\
\text { Sensible Vs. resistente }\end{array}$ & $\begin{array}{l}\text { Valor de } p \\
\text { Sensible Vs. control } \\
\text { (gentamicina) }\end{array}$ & $\begin{array}{c}\text { Valor de p Resistente } \\
\text { Vs. control } \\
\text { (gentamicina) }^{\star \star}\end{array}$ \\
\hline HESMa1 & 35 & 0 & 0 & - & 0,0253 & 0,0253 \\
\hline HESMa1 & 70 & 0 & 0 & - & 0,0253 & 0,0253 \\
\hline HESMa1 & 105 & 0 & 0 & - & 0,0253 & 0,0253 \\
\hline HEHMo2 & 35 & 0 & 0 & - & 0,0253 & 0,0253 \\
\hline HEHMo2 & 70 & 0 & 0 & - & 0,0253 & 0,0253 \\
\hline HEHMo2 & 105 & 0 & 0 & - & 0,0253 & 0,0253 \\
\hline HEHMo3 & 35 & $13(13-13)$ & 0 & 0,0253 & 0,0253 & 0,0253 \\
\hline HEHMo3 & 70 & $22(22-22)$ & 0 & 0,0253 & - & 0,0253 \\
\hline HEHMo3 & 105 & $22(22-22)$ & $12(12-12)$ & 0,0253 & 0,0143 & 0,0253 \\
\hline HEHMa4 & 35 & 0 & 0 & - & 0,0253 & 0,0253 \\
\hline HEHMa4 & 70 & 0 & 0 & - & 0,0253 & 0,0253 \\
\hline HEHMa4 & 105 & 0 & 0 & - & 0,0253 & 0,0253 \\
\hline HESMa5 & 35 & 0 & 0 & - & 0,0253 & 0,0253 \\
\hline HESMa5 & 70 & $15(15-16)$ & $15(15-15)$ & 0,3173 & 0,0339 & 0,0253 \\
\hline HESMa5 & 105 & $17(17-23)$ & $20(20-21)$ & 0,6531 & 0,1213 & 0,0339 \\
\hline HEHMa6 & 35 & $12(12-12)$ & $11(11-11)$ & 0,0253 & 0,0253 & 0,0253 \\
\hline HEHMa6 & 70 & $18(18-19)$ & $18(18-18)$ & 0,1138 & 0,0339 & 0,0253 \\
\hline HEHMa6 & 105 & $22(22-22)$ & $21(21-21)$ & 0,0253 & - & 0,0253 \\
\hline HETMo7 & 35 & 0 & 0 & - & 0,0253 & 0,0253 \\
\hline HETMo7 & 70 & 0 & 0 & - & 0,0253 & 0,0253 \\
\hline HETMo7 & 105 & 0 & 0 & - & 0,0253 & 0,0253 \\
\hline HESMo8 & 35 & $15(15-16)$ & $12(12-13)$ & 0,0431 & 0,0339 & 0,0339 \\
\hline HESMo8 & 70 & $18(18-19)$ & $17(17-18)$ & 0,0431 & 0,0339 & 0,0339 \\
\hline HESMo8 & 105 & $20(20-21)$ & $21(19-21)$ & 0,3458 & 0,0339 & 0,0369 \\
\hline HETMo9 & 35 & $20(20-20)$ & $15(16-15)$ & 0,0339 & 0,0253 & 0,0339 \\
\hline HETMo9 & 70 & $23(23-24)$ & $24(23-24)$ & 0,0431 & 0,0339 & 0,1138 \\
\hline HETMo9 & 105 & $24(24-24)$ & $25(18-25)$ & 1 & 0,0253 & 0,4867 \\
\hline HESMa10 & 35 & $19(19-19)$ & $15(15-16)$ & 0,0339 & 0,0253 & 0,0339 \\
\hline HESMa10 & 70 & $20(20-20)$ & $21(18-21)$ & 1 & 0,0253 & 0,0369 \\
\hline HESMa10 & 105 & $20(20-20)$ & $20(19-20)$ & 0,3173 & 0,0253 & 0,0339 \\
\hline HEHMo11 & 35 & 0 & 0 & - & 0,0253 & 0,0253 \\
\hline HEHMo11 & 70 & $16(16-16)$ & $15(15-15)$ & 0,0253 & 0,0253 & 0,0253 \\
\hline HEHMo11 & 105 & $18(18-18)$ & $15(15-15)$ & 0,0253 & 0,0253 & 0,0253 \\
\hline HEHMo12 & 35 & 0 & 0 & - & 0,0253 & 0,0253 \\
\hline HEHMo12 & 70 & 0 & 0 & - & 0,0253 & 0,0253 \\
\hline HEHMo12 & 105 & 0 & 0 & - & 0,0253 & 0,0253 \\
\hline HESMa13 & 35 & 0 & 0 & - & 0,0253 & 0,0253 \\
\hline HESMa13 & 70 & 0 & 0 & - & 0,0253 & 0,0253 \\
\hline HESMa13 & 105 & 0 & 0 & - & 0,0253 & 0,0253 \\
\hline HEHMa14 & 35 & 0 & 0 & - & 0,0253 & 0,0253 \\
\hline HEHMa14 & 70 & 0 & 0 & - & 0,0253 & 0,0253 \\
\hline HEHMa14 & 105 & 0 & 0 & - & 0,0253 & 0,0253 \\
\hline
\end{tabular}

He: hongo endófito; S: semilla; T: tallo; H: hoja; Mo: M. oleifera; Ma: M. americana

${ }^{*}$ Control de gentamicina en cepas sensibles: $22 \mathrm{~mm} ;{ }^{* *}$ Control de gentamicina en cepas resistentes: 0,0 . Los valores se hallaron por triplicado

(prueba estadística de Mann-Whitney) 
Cuadro 3. Inhibición del crecimiento de cepas sensibles y resistentes de Escherichia coli con extractos de hongos endófitos, comparada con el control de gentamicina

\begin{tabular}{|c|c|c|c|c|c|c|}
\hline $\begin{array}{l}\text { Código } \\
\text { de hongo } \\
\text { endófito }\end{array}$ & $\begin{array}{c}\text { Extracto } \\
\text { etanólico }(\mu \mathrm{l})\end{array}$ & $\begin{array}{c}\text { E. coli sensible } \\
\text { (ATCC 29213) (mm) } \\
\text { Mediana (min.-máx.) }\end{array}$ & $\begin{array}{l}\text { E. coli resistente } \\
\text { (USb007) (mm) } \\
\text { Mediana (min.-máx.) }\end{array}$ & $\begin{array}{c}\text { Valor de } p \\
\text { Sensible Vs. resistente }\end{array}$ & $\begin{array}{c}\text { Valor de } p \\
\text { Sensible Vs. control } \\
\text { (gentamicina) }^{\star}\end{array}$ & $\begin{array}{c}\text { Valor de } p \\
\text { Resistente Vs. control } \\
(\text { gentamicina) }\end{array}$ \\
\hline HESMa1 & 35 & 0 & 0 & - & 0,0495 & - \\
\hline HESMa1 & 70 & $16(16-16)$ & $16(16-16)$ & - & 0,0495 & 0,0253 \\
\hline HESMa1 & 105 & $18(17-18)$ & $17(17-17)$ & 0,11 & 0,0495 & 0,0253 \\
\hline HEHMo2 & 35 & 0 & 0 & - & 1 & - \\
\hline HEHMo2 & 70 & 0 & 0 & - & 1 & - \\
\hline HEHMo2 & 105 & 0 & 0 & - & 1 & - \\
\hline HEHMo3 & 35 & 0 & 0 & - & 1 & - \\
\hline HEHMo3 & 70 & 0 & 0 & - & 1 & - \\
\hline HEHMo3 & 105 & 0 & 0 & - & 1 & - \\
\hline HEHMa4 & 35 & $12(11-12)$ & 0 & 0,0339 & 0,0339 & - \\
\hline HEHMa4 & 70 & $16(15-16)$ & $17(16-17)$ & 0,099 & 0,0339 & 0,0339 \\
\hline HEHMa4 & 105 & $20(15-20)$ & $18(18-18)$ & 0,48 & 0,0339 & 0,0253 \\
\hline HESMa5 & 35 & 0 & 0 & - & 0,0253 & - \\
\hline HESMa5 & 70 & 0 & 0 & - & 0,0253 & - \\
\hline HESMa5 & 105 & $19(19-19)$ & $19(18-19)$ & 0,32 & 0,0253 & 0,0339 \\
\hline HEHMa6 & 35 & $17(17-18)$ & $17(17-17)$ & 0,32 & 0,0339 & 0,0253 \\
\hline HEHMa6 & 70 & $23(22-23)$ & $20(20-22)$ & 0,07 & 0,32 & 0,0339 \\
\hline HEHMa6 & 105 & $24(24-25)$ & $24(23-24)$ & 0,20 & 0,0339 & 0,0339 \\
\hline HETMo7 & 35 & 0 & 0 & & 1 & - \\
\hline HETMo7 & 70 & 0 & 0 & & 1 & - \\
\hline HETMo7 & 105 & 0 & 0 & & 1 & - \\
\hline HESMo8 & 35 & $12(12-12)$ & $12(11-12)$ & 0,32 & 0,0253 & 0,0339 \\
\hline HESMo8 & 70 & $20(19-20)$ & $21(17-21)$ & 0,32 & 0,0339 & 0,0339 \\
\hline HESMo8 & 105 & $22(22-22)$ & $22(20-22)$ & 0,32 & 0,0253 & 0,0339 \\
\hline HETMo9 & 35 & $14(13-14)$ & $14(12-14)$ & 0,80 & 0,0339 & 0,0339 \\
\hline HETMo9 & 70 & $21(21-21)$ & $21(20-21)$ & 0,32 & 0,0253 & 0,0339 \\
\hline HETMo9 & 105 & $23(23-23)$ & $22(22-22)$ & 0,0253 & -- & 0,0253 \\
\hline HESMa10 & 35 & $17(17-17)$ & $12(12-13)$ & 0,0339 & 0,0253 & 0,0339 \\
\hline HESMa10 & 70 & $20(20-20)$ & $20(17-21)$ & 1 & 0,0253 & 0,0369 \\
\hline HESMa10 & 105 & $20(20-20)$ & $20(19-20)$ & 0,32 & 0,0253 & 0,0339 \\
\hline HEHMo11 & 35 & $20(20-20)$ & $18(18-18)$ & 0,0253 & 0,0253 & 0,0253 \\
\hline HEHMo11 & 70 & $21(21-21)$ & $20(20-20)$ & 0,0253 & 0,0253 & 0,0253 \\
\hline HEHMo11 & 105 & $22(22-22)$ & $22(22-22)$ & 1 & 0,0253 & 0,0253 \\
\hline HEHMo12 & 35 & $12(12-12)$ & 0 & 0,0253 & 0,0253 & - \\
\hline HEHMo12 & 70 & $18(18-18)$ & $12(11-12)$ & 0,0253 & 0,0253 & 0,0495 \\
\hline HEHMo12 & 105 & $18(18-18)$ & $15(14-15)$ & 0,0253 & 0,0253 & 0,0495 \\
\hline HESMa13 & 35 & 0 & 0 & & 0,0253 & - \\
\hline HESMa13 & 70 & $14(14-14)$ & $14(13-14)$ & 0,32 & 0,0253 & 0,0339 \\
\hline HESMa13 & 105 & $21(21-21)$ & $20(20-21)$ & 0,11 & 0,0253 & 0,0339 \\
\hline HEHMa14 & 35 & 0 & 0 & & 0,0253 & - \\
\hline HEHMa14 & 70 & $12(12-15)$ & 0 & 0,0253 & 0,339 & - \\
\hline HEHMa14 & 105 & $16(15-16)$ & 0 & 0,0253 & 0,0339 & - \\
\hline
\end{tabular}

He: hongo endófito; S: semilla; T: tallo; H: hoja; Mo: M. oleífera; Ma: M. americana

* Control de gentamicina en cepas sensibles: $23 \mathrm{~mm}{ }^{* *}$ Control de gentamicina en cepas resistentes: 0 . Los valores se hallaron por triplicado (prueba estadística de Mann-Whitney)

los extractos etánolicos fúngicos de los endófitos tendieron a incrementar la inhibición al aumentar la concentración del extracto en la prueba $(p=0,0563$ y $p=0,0672$, respectivamente). Un comportamiento similar se observó al aumentar la concentración de los extractos fúngicos en las pruebas de inhibición del crecimiento de las cepas de $S$. aureus. 


\section{Actividad antimicrobiana y citotoxicidad de los extractos etanólicos crudos derivados de hongos endófitos}

Teniendo en cuenta los resultados arrojados por el análisis estadístico, se consideró continuar con las pruebas de concentración inhibitoria mínima (CIM), concentración bactericida mínima (CBM) y citotoxicidad de los extractos fúngicos de los endófitos identificados como HEHMa6, HESMo8 y HESMa10, correspondientes, respectivamente, a las morfoespecies Penicillium spp., Cladosporium sp., aislamiento 001, y Cladosporium sp., aislamiento 002. Todos los valores hallados en las repeticiones fueron coherentes, ya que arrojaron el mismo valor de CIM. La CIM y la CBM registraron los mismos valores absolutos, con lo que se pudo evidenciar que los extractos tuvieron una capacidad bactericida importante (cuadro 4).

El control con gentamicina se consideró óptimo según los estándares del CLSI. La CIM requerida por las cepas microbianas con cada uno de los tres extractos etanólicos crudos registró diferencias significativas $(p \leq 0,05)$, lo que indica que el extracto HEHMa6 (Penicillium spp.) tuvo mejor bioactividad frente a E. coli. Por el contrario, el extracto HESMo8 (Cladosporium spp.) tuvo mejor bioactividad en $S$. aureus, lo que podría obedecer a factores tales como la composición química de los extractos y su actividad selectiva para microorganismos Gram positivos y Gram negativos. La CBM coincidió con la prueba de CIM, para la cual se consideró una CBM de tres o menos unidades formadoras de colonia (UFC) por caja.

La citotoxicidad de los extractos evaluados en células de mamífero presentó concentraciones $\mathrm{CC}_{50}$ superiores a $1.000 \mu \mathrm{g} / \mathrm{ml}$ (cuadro 4), lo que indicó que los extractos HEHMa6, HESMo8 y HESMa10, obtenidos de los hongos Penicillium spp., Cladosporium sp. 001 y Cladosporium sp.002, respectivamente, no produjeron ningún tipo de daño celular, lo que confirma su utilidad para identificar posibles moléculas bioactivas de interés para su uso en el ser humano.

\section{Identificación de hongos endófitos}

Los 14 hongos filamentosos aislados de los tejidos de $M$. americana y $M$. oleifera que presentaron actividad antimicrobiana contra $E$. coli y $S$. aureus, se identificaron por sus características macroscópicas y microscópicas como miembros de las divisiones Ascomycota y Deuteromycota. Un alto porcentaje $(85 \%)$ de ellos se clasificó como miembro de Ascomycota y, de estos, un $75 \%$ presentó pigmentos intrínsecos en sus hifas y esporas, por

Cuadro 4. Actividades antimicrobianas y citotoxicidad de extractos etanólicos crudos derivados de hongos endófitos (CIM, CMB y $\left.\mathrm{CC}_{50} ; \mu \mathrm{g} / \mathrm{ml}\right)$

\begin{tabular}{|c|c|c|c|c|c|}
\hline Endófitos & $\begin{array}{l}\text { S.aureus } \\
\text { CIM }\end{array}$ & $\begin{array}{l}\text { E. coli } \\
\text { CIM }\end{array}$ & $\begin{array}{l}\text { S. aureus } \\
\text { CMB }\end{array}$ & $\begin{array}{l}\text { E. coli } \\
\text { CMB }\end{array}$ & $\begin{array}{c}\text { Células } \\
\text { Vero }\left(\mathrm{CC}_{50} \pm \mathrm{SD}\right)\end{array}$ \\
\hline $\begin{array}{l}\text { Extracto } \\
\text { HEHMa6 } \\
\text { Penicillium ssp. }\end{array}$ & $2.000 \mu \mathrm{l} / \mathrm{ml}$ & $1.000 \mu \mathrm{l} / \mathrm{ml}$ & $2.000 \mu \mathrm{l} / \mathrm{ml}$ & $1.000 \mu \mathrm{l} / \mathrm{ml}$ & $>1.000$ \\
\hline $\begin{array}{l}\text { Extracto } \\
\text { HESMo8 } \\
\text { Cladosporium (001) }\end{array}$ & $1.000 \mu \mathrm{l} / \mathrm{ml}$ & $2.000 \mu \mathrm{l} / \mathrm{ml}$ & $1.000 \mu \mathrm{l} / \mathrm{ml}$ & $2.000 \mu \mathrm{l} / \mathrm{ml}$ & $>1.000$ \\
\hline $\begin{array}{l}\text { Extracto } \\
\text { HESMa10 } \\
\text { Cladosporium (002) }\end{array}$ & $1.000 \mu \mathrm{l} / \mathrm{ml}$ & $2.000 \mu \mathrm{l} / \mathrm{ml}$ & $>4.000 \mu \mathrm{l} / \mathrm{ml}$ & $1.000 \mu \mathrm{l} / \mathrm{ml}$ & $>1.000$ \\
\hline Gentamicina & $1000 \mu \mathrm{l} / \mathrm{ml}$ & $0,250 \mathrm{l} / \mathrm{ml}$ & $0,125 \mu \mathrm{l} / \mathrm{ml}$ & $0,250 \mu \mathrm{l} / \mathrm{ml}$ & \\
\hline
\end{tabular}

Los resultados se expresan en $\mu \mathrm{g} / \mathrm{ml}$ y son el promedio de tres experimentos independientes.

S. aureus (ATCC 29213), E. coli (ATCC 25922) 
lo cual se clasificaron como Dematiáceos. El $25 \%$ correspondió a hongos de hifas hialinas (cuadro 5). Los hongos clasificados como Deuteromycota se catalogaron como de micelio estéril, ya que sus géneros pertenecen a hongos imperfectos que no presentan esporulación y representaron solo el $15 \%$ de los 14 hongos aislados con actividad antimicrobiana contra las dos bacterias ensayadas (cuadro 5 y figura 2).

\section{Discusión}

Se aislaron 14 hongos endófitos de $M$. americana y M. oleifera con capacidad de inhibir el crecimiento de E. coli y $S$. aureus, lo que evidenció su capacidad de sintetizar una amplia variedad de compuestos naturales bioactivos. En otros estudios de diferentes especies de plantas, se han aislado hongos endófitos con capacidad para inhibir agentes patógenos de animales y plantas, así como de producir diversos antimicrobianos (31-35). El $35 \%$ de los endófitos reportados con actividad antimicrobiana se ha aislado de plantas medicinales (36), como las especies utilizadas en este estudio.

El ensayo dual (hongo-bacterias) realizado preliminarmente permitió una preselección de los hongos endófitos a partir de su capacidad de formar halos de inhibición del crecimiento de S. aureus y E. coli, tanto en cepas ATCC sensibles como en cepas clínicas resistentes a antimicrobianos. Todos los hongos preseleccionados evidenciaron actividad antimicrobiana; el promedio del tamaño de los halos de inhibición fue igual o mayor de $22 \mathrm{~mm}$, excepto contra la cepa resistente de E. coli (USb007), con un promedio de tamaño de halo de $19 \mathrm{~mm}$ (cuadro 1).

Sin embargo, a diferencia de las pruebas del ensayo dual in vitro, no en todas las pruebas de actividad antimicrobiana con extractos etanólicos crudos se presentaron halos de actividad (cuadros 2 y 3 ). Las diferencias halladas con las pruebas de preselección dual podrían estar relacionadas con el hecho de que no todos los metabolitos con actividad antimicrobiana presentes en los hongos endófitos se extraen fácilmente con etanol, por lo cual es necesario extraerlos con otros disolventes orgánicos para recuperar todas las fracciones biológicamente activas. La baja actividad antimicrobiana también podría relacionarse con las concentraciones de los compuestos activos debidas a la cantidad de biomasa. Los extractos crudos filtrados podrían producir compuestos más potentes una vez se sometan a alguna purificación (37).

La identificación hasta el nivel de morfoespecie de los hongos endófitos fúngicos, permitió aislar e identificar en $M$. americana a Bipolaris spp., Aspergillus spp., Penicillium spp., Cladosporium spp. y Mycelia sterilia, las cuales se reportan por primera vez para esta especie vegetal en este trabajo. Algunos de los hongos endófitos aislados en $M$. oleifera han sido reportados previamente en otros estudios $(29,38)$. Los hongos endófitos, como Aspergillus spp., Cladosporium spp. y Mycelia sterilia, comúnmente son aislados tanto en $M$. oleifera como en $M$. americana (cuadro 4). Los extractos fúngicos de los endófitos HEHMa6 (Penicillium spp.), HESMo8 (Cladosporium sp., 001) y HESMa10 (Cladosporium sp., 002), presentaron mayor actividad antibacteriana y, de forma coincidente, los dos aislamientos de los géneros Cladosporium se hicieron a partir de las semillas en las dos plantas utilizadas en este estudio.

En otras especies de plantas, se han aislado especies de Cladosporium spp.como hongos endófitos y se han reportado como fuente importante de antimicrobianos. Los metabolitos de Cladosporium oxiosporum, aislado de 
Cuadro 5. Morfología de los hongos endófitos aislados de Mammea americana y Moringa oleifera

\begin{tabular}{|c|c|c|}
\hline $\begin{array}{l}\text { Código de aislamiento, clasificación } \\
\text { por presencia o ausencia de } \\
\text { pigmento en estructuras fúngicas }\end{array}$ & Género fúngico & Características macroscópicas y microscópicas \\
\hline $\begin{array}{l}\text { HESMa1 } \\
\text { (Dematiáceo) }\end{array}$ & Bipolaris spp. & $\begin{array}{l}\text { Colonias: color gris a café negruzco Reverso: negro } \\
\text { Conidióforos: raquis ramificados, cortos, geniculados o en zigzag } \\
\text { Conidios: elipsoidales, redondeados en ambos extremos y lisos }\end{array}$ \\
\hline $\begin{array}{l}\text { HEHMo2 } \\
\text { (Dematiáceo) }\end{array}$ & Mycelia sterilia & $\begin{array}{l}\text { Morfología similar a la de muchos hongos que se caracterizan por no producir } \\
\text { ningún estado de conidios, sexual o asexual, reconocible en el cultivo. } \\
\text { A nivel microscópico se observan hifas tabicadas con pigmentos oscuros; por } \\
\text { conveniencia, se clasificaron como Mycelia sterilia. }\end{array}$ \\
\hline $\begin{array}{l}\text { HEHMo3 } \\
\text { (Dematiáceo) }\end{array}$ & Curvularia spp. & $\begin{array}{l}\text { Colonias: de crecimiento rápido, parecidas a la gamuza, de color marrón a marrón } \\
\text { negruzco con reverso negro } \\
\text { Conidióforos de forma recta, tabicados, conidios en sucesión simpodia } \\
\text { Conidios de forma semilunar, redondeados en los extremos, de color marrón } \\
\text { pálido, de } 3 \text { tabiques }\end{array}$ \\
\hline $\begin{array}{l}\text { HEHMa6 } \\
\text { (Hialino) }\end{array}$ & Penicillium spp. & $\begin{array}{l}\text { Colonias: verdes con periferia blanca } \\
\text { Reverso: pardo a marrón Conidióforos: hialinos, lisos o de paredes rugosas } \\
\text { Conidios: forman largas cadenas globosas en sucesión basípeta de una célula } \\
\text { conidiógena especializada llamada fiálide. }\end{array}$ \\
\hline $\begin{array}{l}\text { HETMo7 } \\
\text { (Dematiáceo) }\end{array}$ & Alternaria spp. & $\begin{array}{l}\text { Colonias: de color negro a oliváceas. } \\
\text { Reverso: pardo oscuro } \\
\text { Conidióforos: ramificados, cortos Conidios multicelulares, oblicuos, café claro de } \\
\text { paredes lisas }\end{array}$ \\
\hline $\begin{array}{l}\text { HESMo8 } \\
\text { (Dematiáceo) }\end{array}$ & Cladosporium sp. 001 & $\begin{array}{l}\text { Colonias: verde oliva a negro } \\
\text { Reverso: oliváceo a negro } \\
\text { Conidios y conidióforos pigmentados, formándose en cadenas simples y } \\
\text { ramificadas }\end{array}$ \\
\hline $\begin{array}{l}\text { HEHMo11 } \\
\text { (Dematiáceo) }\end{array}$ & Nigrospora sp. 001 & $\begin{array}{l}\text { Colonias: blancas al principio y, al cabo del tercer día, pardas a negras } \\
\text { Reverso: negro } \\
\text { Conidióforos: ramificados, incoloros a pardos } \\
\text { Conidios: negros brillantes, solitarios, simples y esféricos }\end{array}$ \\
\hline $\begin{array}{l}\text { HEHMo12 } \\
\text { (Hialino) }\end{array}$ & Acremonium spp. & $\begin{array}{l}\text { Colonias: de color blanco a gris } \\
\text { Hifas: delgadas, hialinas } \\
\text { Conidios: unicelulares (ameroconidios), hialinos, alargados y algunos cilíndricos que } \\
\text { forman agregados en cabezas viscosas en el ápice de cada filamento o conidióforo }\end{array}$ \\
\hline $\begin{array}{l}\text { HESMa13 } \\
\text { (Dematiáceo) }\end{array}$ & Nigrospora sp. 002 & $\begin{array}{l}\text { Colonias: blancas al principio y, al cabo del tercer día, de color pardo a negro } \\
\text { Reverso: negro } \\
\text { Conidióforos: ramificados, incoloros a pardos } \\
\text { Conidios: negros, solitarios, simples y esféricos }\end{array}$ \\
\hline $\begin{array}{l}\text { HEHMa14 } \\
\text { (Dematiáceo) }\end{array}$ & Mycelia sterilia & $\begin{array}{l}\text { Morfología similar a muchos hongos que se caracterizan porque no producen } \\
\text { ningún estado de conidios, sexual o asexual, reconocible en el cultivo } \\
\text { A nivel microscópico, se observan hifas con pigmentos oscuros, tabicadas. } \\
\text { Por conveniencia, se clasificaron como Mycelia sterilia. }\end{array}$ \\
\hline
\end{tabular}



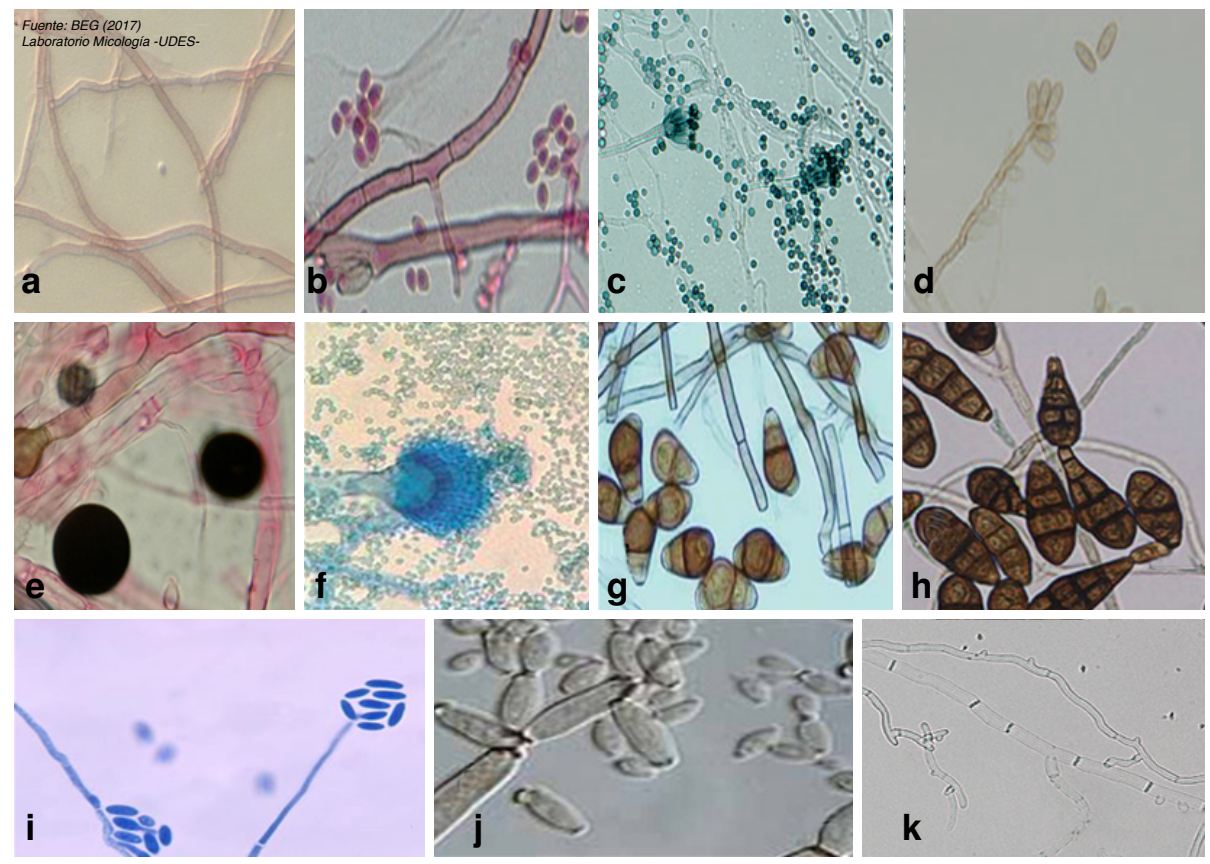

Barra $=25 \mu \mathrm{m}$

Figura 2. Estructuras microscópicas de hongos endófitos aislados de Moringa oleifera y Mammea americana: a) Mycelia sterilia. b) Cladosporium sp. (001). c) Penicillium spp. d) Bipolaris spp. e) Nigrospora spp. f) Aspergillus spp. g) Curvularia spp. h) Alternaria spp. i) Acremonium spp. j) Cladosporium sp. (002). k) Mycelia sterilia.

Aglaia odorata en Indonesia, exhibieron actividad antimicrobiana contra E. coli, S. aureus y Candida albicans (39). En otro estudio, Cladosporium uredinicola, aislado de la fruta Psidium guajava, presentó actividad antimicrobiana contra E. coli, S. aureus, Pseudomonas aeruginosa y Bacillus subtillis (40). Estos hallazgos demuestran la importancia de Cladosporium spp.como un hongo endófito de amplio espectro antimicrobiano.

Se ha aislado Penicillium spp. como endófito en otras especies de plantas, y se ha reportado su actividad antimicrobiana contra E. coli y $S$. aureus (41), con halos de inhibición de $12 \mathrm{~mm}$, siendo estos tamaños más pequeños que los hallados en el presente estudio. Penicillium spp. también se ha reportado como un hongo endófito de $M$. oleifera (42), aunque ni su actividad antimicrobiana en cepas sensibles y resistentes de $E$. coli y $S$. aureu,s ni su aislamiento en la planta $M$. americana, se habían reportado antes.

En Colombia, la identificación y el aislamiento de hongos endófitos han sido escasos. Sin embargo, este tipo de estudio es de mucha relevancia debido a la gran biodiversidad de plantas medicinales del país, las cuales albergan un sinnúmero de comunidades microbianas endófitas con un gran potencial como fuentes naturales de antimicrobianos para el eventual desarrollo de fármacos.

Los resultados obtenidos en este estudio demostraron la diversidad de los géneros fúngicos de endófitos en $M$. americana y $M$. oleifera, y su potencial para la producción de nuevos antibióticos. La complejidad de la identificación de los hongos endófitos, las posibles variaciones morfológicas según los medios de aislamiento micológico y el gran número no cultivable, exigen la utilización de técnicas moleculares para seguir explorando la diversidad de los endófitos en estas plantas medicinales y continuar con el estudio de sus metabolitos como fuentes nuevas de antimicrobianos. 


\section{Agradecimientos}

Al Laboratorio de Biotecnología Agroambiental (LIIBAAM) de la Universidad de Santander, por los espacios ofrecidos para el desarrollo de este trabajo.

\section{Referencias}

1. von Wintersdorff CJH, Penders J, van Niekerk JM, Mills ND, Majumder S, van Alphen LB, et al. Dissemination of antimicrobial resistance in microbial ecosystems through horizontal gene transfer. Front Microbiol. 2016;7:173. https://doi.org/10.3389/fmicb.2016.00173

2. Bisht $D$, Owais $M$, Venkatesan K. Potential of plant-derived products in the treatment of mycobacterial infections. En: Ahmad I, Aqil F, Owais M, editors. Modern phytomedicine: Turning medicinal plants into drugs. Weinheim: Wiley-VCH Verlag GmbH \& Co. KGaA; 2006. p. 295-6. https://doi.org/10.1002/9783527609987.ch14

3. Alvin A, Miller KI, Neilan BA. Exploring the potential of endophytes from medicinal plants as sources of antimycobacterial compounds. Microbiol Res. 2014;169:483-95. https://doi.org/10.1016/j.micres.2013.12.009

4. Bary A. Morphologie und Physiologie der Pilze, Flechten und Myxomyceten. W. Leipzig : W. Engelmann; 1866. p. 21-2. https://doi.org/10.5962/bhl.title.120970

5. Wilson D. Endophyte: The evolution of a term, and clarification of its use and definition. Oikos.1995;73:274-6. https://doi.org/10.2307/3545919

6. Schulz BJ, Boyle C. The endophytic continuum review. Mycol Res. 2005;109:661-86. https://doi.org/10.1017/S095375620500273X

7. Kusari S, Hertweck C, Spiteller M. Chemical ecology of endophytic fungi: Origins of secondary metabolites. Chem Biol. 2012;19:792-8. https://doi.org/10.1016/j.chembiol.2012.06.004

8. Heinig U, Scholz S, Jennewein S. Getting to the bottom of Taxol biosynthesis by fungi. Fungal Divers. 2013;60:161-70. https://doi.org/10.1007/s13225-013-0228-7.

9. Guo B, Dai JR, Ng S, Huang Y, Leong C, Ong W, Carté BK. Cytonic acids A and B: Novel tridepside inhibitors of hCMV protease from the endophytic fungus Cytonaema species. $J$ Nat Prod. 2000;63:602-4. https://doi.org/10.1021/np990467r

10. Mahecha VG, Ovalle EA, Camelo SD, Rozo FA, Barrero BD. Vegetación del territorio CAR: 450 especies de sus llanuras y montañas. Fecha de consulta: 18 de noviembre de 2017. Disponible en: http://biblioteca.humboldt.org.co/cgi-bin/koha/opac-detail. pl?biblionumber $=5243 \&$ query desc=au $\% 2$ Cwrdl $\% 3 A \% 20$ Barrero $\% 20$

11. Little EL, Woodbury R, Wadsworth FH. Trees of Puerto Rico and the Virgin Islands. Fecha de consulta: 20 de noviembre de 2017. Disponible en: http://edicionesdigitales.info/ biblioteca/arbolesprvi2engl.pdf

12. Yang H, Jiang B, Reynertson KA, Basile MJ, Kennelly EJ. Comparative analyses of bioactive Mammea Coumarins from seven parts of Mammea americana by HPLC-PDA with LC-MS. J Agric Food Chem. 2006;54:4114-20. https:/doi.org/10.1021/jf0532462

13. Sánchez-Peña YA, Martínez-Ávila GC, Sinagawa-García SR, Vázquez-Rodríguez JA. Moringa oleifera; importancia, funcionalidad y estudios involucrados. Revista Científica de la Universidad Autónoma de Coahuila. 2013;5:25-30.

14. Fischer HW. Moringa oleifera. Magic, myth or miracle. Salem-USA: Britannia Printing; 2012. p. 50-136.

15. Alfaro N, Martínez W. Uso potencial de la Moringa (Moringa oleifera Lam) para la producción de alimentos nutricionalmente mejorados. Fonacyt. Fecha de consulta: 18 de noviembre de 2017. Disponible en: https://docplayer.es/89330773-Uso-potencial-de-la-moringa-moringaoleifera-lam-para-la-produccion-de-alimentos-nutricionalmente-mejorados.html

16. Souza IF, Napoleão TH, de Sena KX, Paiva PM, de Araújo JM, Coelho LC. Endophytic microorganisms in leaves of Moringa oleifera collected in three localities at Pernambuco State, Northeastern Brazil. Microbiology Research Journal International. 2016;3:1-7 https://doi.org/10.9734/BMRJ/2016/24722

17. Zhao Z, Wang Q, Wang K, Brian K, Liu C, Gu Y. Study of the antifungal activity of Bacillus vallismortis ZZ185 in vitro and identification of its antifungal components. Bioresour Technol. 2010;101:292-7. https://doi.org/10.1016/j. biortech.2009.07.071

18. Echavarría A, D’ Armas H, Matute NL, Jaramillo C, Rojas-de-Astudillo L, Benítez R. Evaluation of antioxidant capacity and secondary metabolites of sixteen medicinal plants extracts. Ciencia Unemi. 2016;9:29-35. 
19. Ahmedkhan $\mathrm{H}$, Ahmad A, Mehboob R. Nosocomial infections and their control strategies. Asian Pac J Trop Biomed. 2015; 5509-14. https://doi.org/10.1016/j.apjtb.2015.05.001

20. Blanco J, Blanco M, Blanco JE, Mora A, Alonso MP, González EA, et al. Enterobacterias: características generales. Género Escherichia. En: Vadillo S, Piriz S, Mateos E, editores. Manual de Microbiología Veterinaria. Madrid: McGraw-Hill Interamericana; 2002. p. 301-25.

21. de la Hoz FJ, Santiago L. Infección urinaria recurrente en la mujer posmenopáusica. Revista Colombiana de Menopausia. 2018:19:3-4.

22. Pigrau C. Infecciones del tracto urinario nosocomiales. Enferm Infect Microbiol Clin. 2013;31:614-24. https://doi.org/ 10.1016/j.eimc.2012.11.015

23. Schulz B, Boyle C. The endophytic continuum. Mycol Res. 2005;109:661-86. https://doi.org/10.1017/S095375620500273X

24. Olaechea PM, Insaustib J, Blanco A, Luque P. Epidemiología e impacto de las infecciones nosocomiales. Medicina Intensiva. 2010;34:256-67. https://doi.org/10.1016/j.medin.2009.11.013

25. Gil de MM. Staphylococcus aureus: microbiología y aspectos moleculares de la resistencia a meticilina. Rev Chil Infectol. 2000;17:145-52. https://doi.org/10.4067/S0716-10182000000200010

26. Carroll K, Hobden J.A, Miller S, Morse S, Mietzner T, Detrick B, et al. Jawetz Melnick \& Adelbergs Medical Microbiology. 27th edition. New York: Mc Graw Hill Education; 2016. p. 363-94.

27. World Health Organization. Global strategy for containment of antimicrobial resistance. Geneve: WHO; 2018. p. 3-4. https:/www.who.int/es/news-room/fact-sheets/detail/ resistencia-a-los-antimicrobianos

28. Unterseher M, Schnittler M. Dilution-to-extinction cultivation of leaf-inhabiting endophytic fungi in beech (Fagus sylvatica L.) -different cultivation techniques influence fungal biodiversity assessment. Mycol Res. 2009;113:645-54. https://doi.org/10.1016/j.mycres.2009.02.002

29. Carbungco ES, Pedroche NB, Panes VA, De la Cruz TE. Identification and characterization of endophytic fungi associated with the leaves of Moringa oleifera Lam. Acta Horticulturae. 2017;1158:373-80. https://doi.org/10.17660/ActaHortic.2017.1158.42

30. Watanabe T. Pictorial Atlas of Soil and Seed Fungi: Morphologies of cultured fungi and key to species. Boca Raton: CRC Press Taylor \& Francis Group; 2010. p. 426.

31. Mishra VK, Passari AK, Chandra P, Leo VV, Kumar B, Uthandi S, et al. Determination and production of antimicrobial compounds by Aspergillus clavatonanicus strain MJ31, an endophytic fungus from Mirabilis jalapa L. using UPLC-ESI-MS/MS and TD-GC-MS analysis. PloS One. 2017;12:e0186234. https://doi.org/10.1371/journal.pone.0186234

32. Liang H, Xing Y, Chen J, Zhang D, Guo S, Wang C. Antimicrobial activities of endophytic fungi isolated from Ophiopogon japonicus (Liliaceae). BMC Complement Altern Med. 2012;12:2-6. https://doi.org/10.1186/1472-6882-12-238

33. Dos Santos IP, da Silva LC, da Silva MV, de Araújo JM, Cavalcanti Mda S, Lima VL. Antibacterial activity of endophytic fungi from leaves of Indigofera suffruticosa Miller (Fabaceae). Front Microbiol. 2015;350:1-7. https://doi.org/10.3389/fmicb.2015.00350

34. Zhao J, Shan T, Mou Y, Zhou L. Plant-derived bioactive compounds produced by endophytic fungi. Mini Rev Med Chem. 2011;11:159-68. https://doi.org/10.2174/138955711794519492

35. Gond SK, Mishra A, Sharma VK, Verma SK, Kumar J, Kharwar RN, et al. Diversity and antimicrobial activity of endophytic fungi from isolated from Nyctanthes arbor-tristis, a well know medicinal plant of India. Mycoscience. 2011;53:113-21. https://doi.org/10.1007/S10267-011-0146-Z

36. Yu H, Zhang L, Li L, Zheng C, Guo L, Li W, et.al. Recent developments and future prospects of antimicrobial metabolites produced by endophytes. Microbiol Res. 2010;165:437-49. https://doi.org/10.1016/j.micres.2009.11.009

37. Idris A, Al-tahir L, Idris E. Antibacterial activity of endophytic fungi extracts from the medicinal plant Kigelia africana. Egypt Acad J Biolog Sci. 2013;5:1-9.

38. Rajeswari S, Umamaheswari S, Prasanth D.A, Rajamanikandan KC. Study of endophytic fungal community of Moringa oleifera from Omalur Region - Salem. Int J Pharm Sci Res. 2014;5:4887-92. https://doi.org/10.13040/IJPSR.0975-8232.5(11).4887-92 
39. Sugijanto EN, Dorra LB. Antimicrobial activity of Cladosporium oxysporum endophytic fungus extract isolated from Aglaia odorata Lour. Indonesian Journal of Medicine. 2016;2:108-15. https://doi.org/10.26911/theijmed.2016.01.02.04

40. de Medeiros LS, Murgu M, de Souza AQ, Rodrigues FO. Antimicrobial depsides produced by Cladosporium uredinicola, an endophytic fungus isolated from Psidium guajava fruits. Helv Chim Acta. 2011;94:1077-84_https://doi.org/10.1002/hlca.201000387

41. Prihanto A, Firdaus M, Nurdiani R. Endophytic fungi isolated from Mangrove (Rhyzopora mucronata) and its antibacterial activity on Staphylococcus aureus and Escherichia coli. J Food Sci Eng. 2011;1:386-9

42. Dhanalakshmi R, Umamaheswari S, Sugandhi P, Prasanth DA. Biodiversity of the endophytic fungi isolated from Moringa oleifera of Yercaud hills. Int J Pharm Sci Res. 2013;4:1064-8. https://doi.org/10.13040/IJPSR.0975-8232.4(3).1064-68 